Published in final edited form as:

Eur J Haematol. 2018 October ; 101(4): 532-541. doi:10.1111/ejh.13140.

\title{
Exercise Capacity and Clinical Outcomes in Adults Followed in the Cooperative Study for Sickle Cell Disease (CSSCD)
}

\author{
Sherif M. Badawy, MD, MS ${ }^{1,2}$, Amanda B. Payne, MPH $^{3}$, Mark J. Rodeghier, PhD $^{4}$, and \\ Robert I. Liem, MD, MS ${ }^{1,2}$ \\ ${ }^{1}$ Division of Hematology, Oncology and Stem Cell Transplant, Ann \& Robert H. Lurie Children's \\ Hospital of Chicago, Chicago, IL \\ 2Department of Pediatrics, Northwestern University Feinberg School Medicine, Chicago, IL \\ ${ }^{3}$ Division of Blood Disorders, National Center on Birth Defects and Developmental Disabilities, \\ Centers for Disease Control and Prevention, Atlanta, GA \\ ${ }^{4}$ Rodeghier Consultants, Chicago, IL, USA
}

\begin{abstract}
Objectives: To determine factors associated with exercise capacity in adults with sickle cell disease (SCD) and its relationship to hospitalizations and mortality.

Methods: A total of 223 participants in the Cooperative Study of Sickle Cell Disease (CSSCD) ( $64 \%$ female, $70 \%$ hemoglobin $\mathrm{SS} / \mathrm{S} \beta^{0}$ thalassemia, mean age $43.3 \pm 7.5$ years) underwent maximal exercise testing using a treadmill protocol with a mean duration of $11.6 \pm 5.2$ minutes.
\end{abstract}

Results: Female sex $(\beta=-3.34,95 \%$ CI $[-1.80,-4.88], p<0.001)$, older age $(\beta=-0.14,95 \%$ CI $[-0.24,-0.04], p=0.005)$, higher body mass index ( $\beta=-0.23,95 \%$ CI $[-0.37,-0.10] ; p=$ $0.001)$ and lower hemoglobin ( $\beta=0.56,95 \% \mathrm{CI}[0.08,1.04], p=0.02)$ were independently associated with lower fitness, while there was a trend with abnormal pulmonary function testing ( $\beta$ $=-1.42,95 \% \mathrm{CI}[-2.92,0.07] ; p=0.06)$. Lower percent predicted forced expiratory volume in 1 second $\left(\mathrm{FEV}_{1}\right)$ was independently associated with lower fitness ( $\beta=0.08,95 \% \mathrm{CI}[0.03,0.13], p$ $=0.001$ ). Genotype and hospitalization rates for pain and acute chest syndrome (ACS) prior to testing were not associated with exercise capacity. Baseline exercise capacity predicted neither future pain or ACS nor survival in our cohort. Adults with SCD tolerated maximal exercise testing.

Conclusions: Prospective studies are needed to further evaluate the impact of regular exercise and improved fitness on clinical outcomes and mortality in SCD.

\section{Keywords}

Sickle cell disease; exercise capacity; fitness; pain; acute chest syndrome; mortality

Correspondence: Sherif M. Badawy, MD, MS, MBBCh, Attending Physician, Department of Pediatrics, Division of Hematology, Oncology and Stem Cell Transplant, Ann \& Robert H. Lurie Children's Hospital, 225 E. Chicago Ave., Box \#30, Chicago, IL, 60611, office: 312-227-4836, fax: 312-227-9376, sbadawy @luriechildrens.org.

Conflict of interest: None of the authors have conflict of interest related to the submitted work. 


\section{Introduction}

Sickle cell disease (SCD) is a common, potentially life-threating inherited hemoglobin disorder affecting approximately 100,000 individuals in the United States. ${ }^{1}$ Complications of SCD range from intermittent debilitating pain episodes, acute chest syndrome (ACS), chronic hemolytic anemia, cardiopulmonary disease, and stroke to long-term end organ damage. ${ }^{2}$ As such, these complications lead to substantial declines in patients' health-related quality of life across the lifespan. ${ }^{3-6}$ In particular, overall physical functioning and exercise capacity are significantly reduced among individuals with SCD. ${ }^{7-12}$ Chronic anemia and cardiopulmonary disease may contribute to this impact of SCD on exercise capacity.

Various clinical and laboratory factors have been associated with increased morbidity and early mortality in patients with SCD, including renal failure, ${ }^{13,14}$ pulmonary hypertension, ${ }^{15,16}$ low forced expiratory volume in 1 second $\left(\mathrm{FEV}_{1}\right),{ }^{17}$ history of smoking, ACS, asthma and/or wheezing, ${ }^{14,18-21}$ seizures, ${ }^{14}$ high white cell count (WBC), low fetal hemoglobin $(\mathrm{HbF}),{ }^{14}$ and laboratory markers suggestive of severe hemolysis. ${ }^{22-24}$ Exercise capacity, also referred to as cardiopulmonary fitness in the epidemiology literature, represents one of the most important predictors of all cause mortality in the general adult population as well as among adults with chronic medical conditions. ${ }^{25-31}$ Fitness may play an important independent protective role through its influence on various risk factors of cardiovascular disease such as hypertension, diabetes, and hypercholesterolemia, the development of which could explain the relationship between mortality and low fitness. ${ }^{32-36}$ While earlier studies have underscored the contribution of fitness to clinical outcomes, including disease-related morbidity and mortality, in the general population, no studies have investigated this relationship in SCD.

The objectives of this secondary analysis were to: 1) determine the factors associated with baseline exercise capacity in a cohort of adults with SCD, and 2) evaluate the relationship of exercise capacity to hospitalization for pain and ACS and overall mortality. We hypothesized that clinical factors such as age, sex, hemoglobin, SCD genotype and cardiopulmonary disease significantly affect exercise capacity, and that reduced exercise capacity is a predictor of more frequent hospitalizations for pain and ACS and higher mortality in adults with SCD.

\section{Methods}

\section{Patient population}

A cohort was constructed using data from the Cooperative Study of Sickle Cell Disease (CSSCD), a prospective cohort study designed to investigate the natural history of SCD. The CSSCD cohort has been previously described ${ }^{37}$ Data from participants enrolled in the Phase 2A continuation study were used for this analysis. The Phase $2 \mathrm{~A}$ continuation study was designed to examine the progression of organ damage in adult CSSCD participants born before January 1, 1956, enrolled between March 1979 and May 1981, at 11 of the original 23 participating centers. Participants in Phase 2A underwent annual physical exams and completed exercise and pulmonary function testing at Phase 2A enrollment and exit visits. Excluded from this study were participants who did not complete exercise testing $(\mathrm{N}=75)$ for 
reasons that were not reported, had exercise data that did not pass quality control for the CSSCD dataset $(\mathrm{N}=25)$, had missing laboratory and/or pulmonary function measurements $(\mathrm{N}=9)$, had contraindications for exercise testing $(\mathrm{N}=10)$, and had missing data related to exercise duration $(\mathrm{N}=17)$ (Figure 1).

\section{Mortality and follow-up time}

Date and cause of death were recorded during Phase 2A follow-up; however, autopsy information was not routinely available. Follow-up time was computed as the time between the completion of the first exercise test and death, recorded date of final disposition, or September 30, 1993 (the date of the end of Phase 2A data collection), whichever came first.

\section{Pain and acute chest syndrome hospitalization rates}

Vaso-occlusive pain events were defined as previously described (events lasting at least two hours that resulted in a healthcare provider visit and that could not be explained by any other reason than SCD) ${ }^{38}$ ACS events were also defined as previously described (a new radiodensity on chest imaging with or without respiratory symptoms accompanied by fever).

${ }^{39}$ Rates were defined as the number of events occurring during the follow-up period divided by the total follow-up time.

\section{Measures of exercise capacity}

Data from the first exercise test upon enrollment in Phase 2A were used for this study. Test data were reviewed centrally for quality. Participants underwent a maximal treadmill test using a modified Balke protocol, which consisted of 10 stages of exercise lasting 2 minutes each. Treadmill speed was kept constant at $2 \mathrm{mph}$. Incline was initially set at $0 \%$ followed by a $2.5 \%$ increase at each stage. Breath-by-breath gas exchange data were not measured during exercise. Test termination occurred at either volitional exhaustion or the discretion of the physician supervising the test for medical reasons. Exercise capacity in this analysis was defined by total number of minutes spent on the treadmill. Although maximal oxygen consumption $\left(\mathrm{VO}_{2} \mathrm{max}\right)$ is considered the gold standard for defining exercise capacity, treadmill duration is considered an acceptable surrogate and is commonly adopted in other published epidemiological studies of fitness in which direct gas exchange is not performed during exercise testing. ${ }^{29,40-43}$ Additionally, peak METS reported in the CSSCD were calculated using the equation METS $=\mathrm{VO}_{2} \mathrm{max} / 3.5 \mathrm{~mL} / \mathrm{kg} / \mathrm{min}$, in which $\mathrm{VO}_{2}$ max was estimated through previously published prediction equations. ${ }^{44,45}$

\section{Other predictors}

Other predictors of mortality, pain and ACS rates, and/or exercise capacity included age, genotype, baseline hemoglobin, baseline WBC, hydroxyurea and/or chronic transfusion use, and retrospective pain and acute chest syndrome rates. Age was defined as the age at time of exercise testing. Genotype was determined by cellulose acetate hemoglobin electrophoresis and quantitative chromatography at the Centers for Disease Control and Prevention. Baseline hemoglobin and WBC were defined using data from steady-state laboratory evaluation closest to the date of exercise testing. Hydroxyurea and chronic transfusion use were collected in the clinical record. Retrospective pain and acute chest syndrome rates were 
defined using follow-up data collected during Phase 1 of CSSCD and calculated over the three years prior to exercise testing. Tricuspid regurgitant jet velocity (TRJV) data on echocardiography were not included in our analysis due to a large number of missing values and the inability to confirm standardized procedures for their measurements in the CSSCD.

Data from the pulmonary function testing (PFT) completed closest to the exercise testing date were also used for this study. Test data were reviewed centrally for quality. Percent predicted values for $\mathrm{FEV}_{1}$, Forced Vital Capacity (FVC), and the ratio of $\mathrm{FEV}_{1} / \mathrm{FVC}$ were calculated using the Global Lung Initiative 2012 regression equations. ${ }^{46}$ Percent predicted values were classified as below the lower limit of normal if they were below the $5^{\text {th }}$ percentile for age, sex, race, and height. ${ }^{46}$ Percent predicted values for Total Lung Capacity (TLC) were obtained using previously-published prediction equations ${ }^{46,47}$ and were adjusted by $12 \% 48$ to account for the effect of race. A percent predicted TLC value less than $80 \%$ was considered abnormal. Participants were categorized as having normal, obstructive, restrictive, or mixed pulmonary function patterns using predicted $\mathrm{FEV}_{1}, \mathrm{FVC}, \mathrm{FEV}_{1} / \mathrm{FVC}$, and TLC criteria previously published by the American Thoracic Society/European Respiratory Society. ${ }^{49}$

\section{Statistical analysis}

Standard descriptive analysis was performed for categorical data using Pearson's chi-square test or Fisher's exact test, where appropriate. Continuous data that were normally distributed were analyzed using t-tests or ANOVA; data with a non-normal distribution were analyzed with the Mann Whitney Wilcoxon, Wilcoxon signed ranks, or Kruskal-Wallis tests. Tobit regression was used to evaluate factors associated with exercise capacity (treadmill duration). Negative binomial regression was used to evaluate factors associated with prospective rates of ACS and pain to end of follow-up. Kaplan-Meier product estimation and Cox proportional hazards regression were used to evaluate factors associated with survival to the end of follow-up. In all regression models, variables were entered in one step. Postestimation analysis was performed to check model assumptions and potentially influential observations. Analyses were performed using IBM SPSS Statistics (Version 23, Armonk, NY: IBM Corp.) or Stata Statistical Software (Release 14, College Station, TX: StataCorp LP).

\section{Results}

\section{Participant characteristics}

A total of 223 African-American adults with SCD completed at least 1 exercise test and were followed for an average of $3.1 \pm 0.5$ years. Participants ( $64 \%$ female, $70 \%$ with hemoglobin SS or $S / \beta^{0}$ thalassemia, mean age $43.3 \pm 7.5$ years) had mean hemoglobin of 9.1 $\pm 2.2 \mathrm{~g} / \mathrm{dl}$. In the CSSCD Phase 2A study cohort, the baseline clinical characteristics of adult African-American participants with SCD who completed exercise testing $(\mathrm{N}=223)$ compared with those who did not $(\mathrm{N}=136)$ are shown in Table 1 . Characteristics were not significantly different between groups except that participants who completed exercise testing had longer duration of follow up, lower annual rate of pain episodes and lower mortality, when compared with those who did not. 


\section{Exercise capacity in the CSSCD cohort}

Participants lasted a mean of $11.6 \pm 5.2$ minutes on the treadmill with $87 \%$ completing $\geq 3$ stages but only $17 \%$ reaching stage 9 or 10 . Participants' exercise data are summarized in Table 2. Of the 223 eligible participants who completed first exercise testing, only 100 (45\%) completed a second exercise test, which occurred a mean of $2.2 \pm 0.5$ years after the first. Exercise data were not significantly different between exercise tests (Table 2). However, more participants reported dyspnea during the second test.

We categorized exercise capacity as low, medium and high based on tertiles of treadmill duration with an average of $5.7 \pm 1.9$ minutes in the low tertile, $11.8 \pm 1.6$ minutes in the intermediate tertile, and 18.1 \pm 2.1 minutes in the high tertile (Table 3). Across tertiles of exercise capacity, participants in the high tertile were more likely to be males (\% males 60 vs. 29 vs. $23 \%, p<0.001$ ), of younger age (mean age 41.3 vs. 43.1 vs. 45.2 years old, $p=$ 0.007 ) and to have higher baseline hemoglobin (mean hemoglobin 9.8 vs. 9.0 vs. $8.5 \mathrm{~g} / \mathrm{dl}, p$ $=0.003$ ), when compared to those in the intermediate and low tertiles. Moreover, participants in the low tertile were more likely to have abnormal PFT results ( $\%$ abnormal PFT 58 vs. 35 vs. $39 \%, p=0.008$ ) or lower $\mathrm{FEV}_{1}$ (mean $\mathrm{FEV}_{1} \%$ predicted 74.7 vs. 81.9 vs. $85.8 \%$ predicted, $p=0.002$ ), when compared to participants in the high and intermediate tertiles. Pain or ACS hospitalization rates during the 3 years prior to exercise testing were not significantly different across high, intermediate and low tertiles of exercise capacity.

\section{Predictors of baseline exercise capacity}

In a multivariable tobit regression model, female $\operatorname{sex}(\beta=-3.34,95 \% \mathrm{CI}[-1.80,-4.88] ; p<$ $0.001)$, older age at the time of exercise testing ( $\beta=-0.14,95 \% \mathrm{CI}[-0.24,-0.04] ; p=$ $0.005)$, higher body mass index (BMI) at study entry ( $\beta=-0.23$, 95\% CI $[-0.37,-0.10] ; p=$ $0.001)$, and lower hemoglobin ( $\beta=0.56,95 \% \mathrm{CI}[0.08,1.04] ; p=0.02)$ were independently associated with lower baseline exercise capacity (i.e. shorter duration on treadmill), with abnormal PFT trending toward significance in its association with lower exercise capacity ( $\beta$ $=-1.42,95 \% \mathrm{CI}[-2.92,0.07] ; p=0.06)$ (Table 4). Lower percent predicted $\mathrm{FEV}_{1}$, however, was independently associated with lower exercise capacity ( $\beta=0.08,95 \%$ CI [0.03, 0.13], $p$ $=0.001)$ if used instead of abnormal PFT in an alternative model (supplemental Table 1). Genotype (HbSS or $\mathrm{HbS} / \beta^{0}$ thalassemia) and hospitalization rates for pain and ACS prior to exercise testing were not significantly associated with exercise capacity.

\section{Relationship of exercise capacity to prospective pain or acute chest syndrome and mortality}

In a negative binomial regression model, we found that exercise capacity did not predict future pain (incidence rate ratio $(\mathrm{IRR})=1.0 ; 95 \% \mathrm{CI}[0.91,1.10] ; p=0.92$ ) or ACS episodes $($ IRR $=0.95 ; 95 \%$ CI $[0.85,1.07] ; p=0.41)$ after adjustment for age, sex, genotype and hemoglobin (Table 5). Using the same model, only pain (IRR $=3.29 ; 95 \%$ CI $[2.56,4.23] ; p$ $<0.001$ ) and ACS hospitalization rates (IRR $=31.60 ; 95 \%$ CI $[4.68,213.48] ; p<0.001$ ) prior to exercise testing predicted future pain or ACS episodes.

Death was reported in only 9 out of 191 participants $(4.7 \%)$ in our cohort, all of whom had either hemoglobin SS or $S / \beta^{0}$ thalassemia. Survival was not significantly different across 
tertiles of exercise capacity (Supplemental Figure 1). Using a Cox regression model, exercise capacity did not predict survival in our cohort (hazard ratio (HR) $=0.98 ; 95 \% \mathrm{CI}$ $[0.85,1.13] ; p=0.82)$. Similarly, age at exercise testing and abnormal PFT were not predictors of mortality. However, male sex $(\mathrm{HR}=6.5 ; 95 \%$ CI $[1.2,33.9] ; p=0.02)$ and lower hemoglobin ( $\mathrm{HR}=0.55 ; 95 \%$ CI $[0.37,0.84] ; p=0.005)$ were independent predictors of mortality (Table 6).

\section{Discussion}

This retrospective analysis from the CSSCD represents the largest study to date of exercise capacity in adults with SCD. Few adults with SCD in the CSSCD could complete all 10 stages of a standard Balke treadmill exercise test. We found that lower exercise capacity in adults with SCD is independently associated with female sex, older age, higher BMI and lower $\mathrm{Hb}$. Although the least fit participants were more likely to have lung disease on PFT both by conventional ATS classification and by $\mathrm{FEV}_{1}$ alone, only the association between percent predicted $\mathrm{FEV}_{1}$ and exercise capacity was significant in our multivariable model. Moreover, we found that baseline exercise capacity neither was associated with nor predicted pain and ACS hospitalizations by either retrospective or prospective analysis, respectively. Baseline exercise capacity in adults with SCD in this study also did not predict future mortality.

Few studies in the literature have directly examined exercise capacity in the adult SCD population through formal exercise testing. ${ }^{8,12,50-54}$ Compared to that in our study, sample sizes in previously published studies have been relatively small. A major challenge to comparing the results from our study to data in other studies is the variability among studies in exercise testing protocols. These differences pertain to required effort (maximal versus submaximal), type of machine (cycle versus treadmill) and whether or not breath-by-breath, gas exchange was directly measured. In contrast to ours, other studies have focused on using gas exchange data to characterize cardiopulmonary responses during exercise challenge or on examining the relationship between fitness and specific cardiopulmonary complications such as pulmonary hypertension. ${ }^{50,52}$ Although breath-by-breath gas exchange was not employed as part of the exercise testing performed in the CSSCD study, the Balke treadmill protocol is commonly used in large-scale epidemiology studies of fitness in the general population. ${ }^{55-57}$ Importantly, our study supports the safety of maximal exercise testing using a protocol such as the Balke treadmill test in adults with SCD.

It was not surprising that exercise capacity was low among participants in the CSSCD cohort. Differences in exercise protocols and measurements used to define exercise capacity and fitness across the literature make it difficult to directly compare exercise capacity measured in the CSSCD to that reported in other studies. Whether we use estimated $\mathrm{VO}_{2}$ max derived from treadmill duration or METS calculated from $\mathrm{VO}_{2}$ max to define exercise capacity, exercise capacity in the CSSCD cohort was lower compared to levels reported in the literature for the general black population, for which fitness is already known to be lower compared to other race groups. ${ }^{58}$ Mean estimated $\mathrm{VO}_{2}$ max, for example, in the CSSCD participants was lower than that measured even for the lowest fitness group in NHANES study. 59 
We found that male sex, lower age, higher $\mathrm{Hb}$ and lower $\mathrm{BMI}$ were associated with better exercise capacity in participants in the CSSCD. Although this finding is not surprising given that these variables are known to be associated with fitness in the general population as well as in children and adolescents with sickle cell anemia, it further elucidates the contributions to exercise capacity in adults with SCD, for whom very little is currently known. $9,41,60-62$. We also found that having had an abnormal PFT in the CSSCD was associated with decreased exercise capacity on bivariate analysis and trended toward significance in our multivariable model. This finding is supported by the known relationship between reduced fitness and poor lung function in other disease populations such as COPD or conditions associated with restrictive lung disease. ${ }^{63-67}$ In our analysis, we were not able to specifically examine the effect of restrictive versus obstructive lung disease on exercise capacity given the number of participants in the CSSCD with mixed patterns on PFT. Nonetheless, our finding that lower $\mathrm{FEV}_{1}$ itself is independently associated with lower exercise capacity in adults with SCD warrants further investigation since greater annual declines in $\mathrm{FEV}_{1}$ has also been associated with greater reductions in fitness among young adults in the general population. ${ }^{68}$

Our results did not support our hypothesis of an association between exercise capacity and overall mortality. This is in contrast to studies that suggest cardiopulmonary fitness is an important predictor of all-cause mortality in the general population as well as in other chronic conditions. ${ }^{29,69-71}$ However, the small number of deaths in the CSSCD cohort and relative short follow-up may have affected our ability to discern a relationship. The group of SCD patients that made it into adulthood during this era or was able to complete maximal exercise testing may also have been inherently healthier. Although most clinical and laboratory characteristics were not different in patients who did versus did not undergo exercise testing, pain hospitalization rates and mortality were higher in patients who did not complete baseline exercise testing. Nonetheless, it was still valuable to examine the relationship between mortality and exercise capacity despite the possibility for a sampling bias that resulted in a "healthier" group of patients completing exercise testing. More feasible strategies may be needed in SCD to measure exercise capacity such as 6-minute walk distance or submaximal exercise testing, which may improve our ability to evaluate the relationship between exercise capacity and mortality. Finally, low exercise capacity in SCD is multifactorial in etiology and despite the known impact of cardiopulmonary complications on exercise capacity in SCD, mortality may be more directly associated with these complications or other pathophysiologic sequelae themselves rather than with reduced exercise capacity.

It was surprising that we did not find a relationship between exercise capacity and traditional indices of disease severity such as hospitalization for pain and ACS. This suggests that reduced exercise capacity in SCD could be more a function of physiologic derangements in exercise responses and less a function of absolute reductions in physical activity or increase in sedentary behavior, which might be expected of higher hospitalization rates for diseaserelated complications. Similar to other aspects of our analysis, existing studies that have examined this relationship in SCD are limited by variability in their approach to measuring exercise capacity and physical functioning as well as by their chosen outcomes of disease severity. In studies focusing on exercise capacity, reduced exercise capacity by 6-minute 
walk distance or exercise testing in SCD has been associated with complications such as elevated TRJV, recurrent ACS or silent stroke. ${ }^{10,50,72}$ In studies that focus instead on general physical functioning, poor self-reported physical functioning on HRQOL assessments is associated with increased pain. 3,73

The retrospective nature of our analysis may have impacted our interpretation of the exercise test results. In the CSSCD, exercise testing was terminated by volitional exhaustion rather than using more objective criteria to assess maximal effort such as serum lactate or respiratory exchange ratio. However, maximal heart rates recorded for subjects at the end of exercise testing were on average about $85 \%$ of predicted maximal heart rates, which supports the maximal nature of testing in the CCSCD. Although quality control of exercise testing in the CSSCD could not be fully assessed, rigor could in part be assumed given the study's adoption of the modified Balke protocol, a well accepted and validated exercise test, as well as the completeness of the data elements collected during testing. Since breath-bybreath gas exchange data were not collected during exercise testing in the CSSCD study, we could not directly measure $\mathrm{VO}_{2}$ or analyze specific parameters that allow for a deeper understanding of the cardiopulmonary response to exercise. Nonetheless, we used treadmill duration as a surrogate for exercise capacity and fitness in our study, which represents a common approach used in several other landmark epidemiological studies of fitness. ${ }^{29,40-43}$ Finally, given the high degree of missing exercise data from the $2^{\text {nd }}$ tests originally planned for this cohort, we could not assess change in fitness, which compared to baseline fitness may represent a more important risk predictor for mortality in SCD.

Several other limitations of our study warrant discussion. Participants enrolled in the CSSCD may not accurately reflect a contemporary cohort of adults with SCD given the inception date of the CSSCD, thus reducing the overall generalizability of our findings. The ability to reach adulthood in this era while living with SCD may have introduced a selection or survival bias toward the healthiest adults enrolled in the CSSCD. Moreover, a large number of participants did not undergo exercise testing, and we were unable to determine if more severe disease precluded some participants from undergoing exercise testing. Still, our cohort was large enough to include some deaths and more importantly, allowed us to examine other surrogates of disease severity such as pain and ACS hospitalizations. Another limitation of this study was our exclusion of TRJV, a known predictor of mortality in SCD, due to the large number of patients for whom TRJV was unquantifiable. The inability to differentiate unquantifiable from missing values due to technical challenges may explain why TRJV data has been omitted from published studies of CSSCD data to date. We did not look for other evidence of cardiac disease on echocardiography given that measurements required to diagnose diastolic dysfunction, for example, are also prone to technical error and assessing the quality of these measurements was beyond the scope of our analysis. Finally, although elevated $\mathrm{N}$-terminal pro brain natriuretic peptide level may be a surrogate marker for pulmonary vascular disease, these data were not publically available through the NHLBI's BioLink dataset for the CSSCD study.

In conclusion, data from this study corroborate findings from other studies that have demonstrated poor exercise capacity in adults with SCD. Our results suggest that maximal exercise testing in adults with SCD is feasible and safe. Besides other known risk factors, 
having an abnormal PFT or low percent-predicted $\mathrm{FEV}_{1}$ may be associated with reduced exercise capacity in SCD. Hospitalization for pain or ACS, however, was not associated with reduced fitness levels. Given its utility as a prognostic biomarker in other populations, future prospective studies are warranted to further study exercise capacity and cardiopulmonary fitness, as well as change in fitness over time, and their relationship to disease severity and mortality in SCD.

\section{Supplementary Material}

Refer to Web version on PubMed Central for supplementary material.

\section{Acknowledgements}

We thank the National Health, Lung and Blood Institute (NHLBI) Biologic Specimen and Data Repository Information Coordinating Center for providing access to the data from the Cooperative Study of Sickle Cell Disease (CSSCD) Phase 2A. The findings and conclusions in this report are those of the author(s) and do not necessarily represent the official position of the Centers for Disease Control and Prevention. This project was supported by grant number K12HS023011 from the Agency for Healthcare Research and Quality. The content is solely the responsibility of the authors and does not necessarily represent the official views of the Agency for Healthcare Research and Quality.

\section{References}

1. National Heart, Lung and Blood Institute. What Is Sickle Cell Anemia? 2012; http:// www.nhlbi.nih.gov/health/health-topics/topics/sca/ (Accessed January 6, 2018).

2. Rees DC, Williams TN, Gladwin MT. Sickle-cell disease. Lancet 2010;376(9757):2018-2031. [PubMed: 21131035]

3. Dampier C, LeBeau P, Rhee S, et al. Health-related quality of life in adults with sickle cell disease (SCD): a report from the comprehensive sickle cell centers clinical trial consortium. Am J Hematol 2011;86(2):203-205. [PubMed: 21264908]

4. Panepinto JA, Bonner M. Health-related quality of life in sickle cell disease: past, present, and future. Pediatr Blood Cancer 2012;59(2):377-385. [PubMed: 22522407]

5. Badawy SM, Thompson AA, Lai JS, Penedo FJ, Rychlik K, Liem RI. Health-related quality of life and adherence to hydroxyurea in adolescents and young adults with sickle cell disease. Pediatr Blood Cancer 2016.

6. Dampier C, Lieff S, LeBeau P, et al. Health-related quality of life in children with sickle cell disease: a report from the Comprehensive Sickle Cell Centers Clinical Trial Consortium. Pediatr Blood Cancer 2010;55(3):485-494. [PubMed: 20658620]

7. Braden DS, Covitz W, Milner PF. Cardiovascular function during rest and exercise in patients with sickle-cell anemia and coexisting alpha thalassemia-2. Am J Hematol 1996;52(2):96-102. [PubMed: 8638648]

8. Callahan LA, Woods KF, Mensah GA, Ramsey LT, Barbeau P, Gutin B. Cardiopulmonary responses to exercise in women with sickle cell anemia. Am J Respir Crit Care Med 2002;165(9):1309-1316. [PubMed: 11991885]

9. Liem RI, Reddy M, Pelligra SA, et al. Reduced fitness and abnormal cardiopulmonary responses to maximal exercise testing in children and young adults with sickle cell anemia. Physiol Rep 2015;3(4).

10. Liem RI, Nevin MA, Prestridge A, Young LT, Thompson AA. Functional capacity in children and young adults with sickle cell disease undergoing evaluation for cardiopulmonary disease. Am J Hematol 2009;84(10):645-649. [PubMed: 19705433]

11. Sachdev V, Kato GJ, Gibbs JS, et al. Echocardiographic markers of elevated pulmonary pressure and left ventricular diastolic dysfunction are associated with exercise intolerance in adults and adolescents with homozygous sickle cell anemia in the United States and United Kingdom. Circulation 2011;124(13):1452-1460. [PubMed: 21900080] 
12. van Beers EJ, van der Plas MN, Nur E, et al. Exercise tolerance, lung function abnormalities, anemia, and cardiothoracic ratio in sickle cell patients. Am J Hematol 2014;89(8):819-824. [PubMed: 24799296]

13. McClellan AC, Luthi JC, Lynch JR, et al. High one year mortality in adults with sickle cell disease and end-stage renal disease. Br J Haematol 2012;159(3):360-367. [PubMed: 22967259]

14. Platt OS, Brambilla DJ, Rosse WF, et al. Mortality in sickle cell disease. Life expectancy and risk factors for early death. N Engl J Med 1994;330(23):1639-1644. [PubMed: 7993409]

15. Gladwin MT, Sachdev V, Jison ML, et al. Pulmonary hypertension as a risk factor for death in patients with sickle cell disease. N Engl J Med 2004;350(9):886-895. [PubMed: 14985486]

16. Mehari A, Alam S, Tian X, et al. Hemodynamic predictors of mortality in adults with sickle cell disease. Am J Respir Crit Care Med 2013;187(8):840-847. [PubMed: 23348978]

17. Kassim AA, Payne AB, Rodeghier M, Macklin EA, Strunk RC, DeBaun MR. Low forced expiratory volume is associated with earlier death in sickle cell anemia. Blood 2015;126(13): 1544-1550. [PubMed: 26261241]

18. Knight-Madden JM, Barton-Gooden A, Weaver SR, Reid M, Greenough A. Mortality, asthma, smoking and acute chest syndrome in young adults with sickle cell disease. Lung 2013;191(1):95100. [PubMed: 23149803]

19. Boyd JH, Macklin EA, Strunk RC, DeBaun MR. Asthma is associated with increased mortality in individuals with sickle cell anemia. Haematologica 2007;92(8):1115-1118. [PubMed: 17650441]

20. Cohen RT, Madadi A, Blinder MA, DeBaun MR, Strunk RC, Field JJ. Recurrent, severe wheezing is associated with morbidity and mortality in adults with sickle cell disease. Am J Hematol 2011;86(9):756-761. [PubMed: 21809369]

21. Dhakal B, Giese K, Santo-Thomas L, Field JJ. Death during an asthma exacerbation in an adult with sickle cell disease: an autopsy case study. Am J Hematol 2013;88(9):824. [PubMed: 23720156]

22. Kato GJ, McGowan V, Machado RF, et al. Lactate dehydrogenase as a biomarker of hemolysisassociated nitric oxide resistance, priapism, leg ulceration, pulmonary hypertension, and death in patients with sickle cell disease. Blood 2006;107(6):2279-2285. [PubMed: 16291595]

23. Taylor JGt, Nolan VG, Mendelsohn L, Kato GJ, Gladwin MT, Steinberg MH. Chronic hyperhemolysis in sickle cell anemia: association of vascular complications and mortality with less frequent vasoocclusive pain. PLoS One 2008;3(5):e2095. [PubMed: 18461136]

24. Nouraie M, Lee JS, Zhang Y, et al. The relationship between the severity of hemolysis, clinical manifestations and risk of death in 415 patients with sickle cell anemia in the US and Europe. Haematologica 2013;98(3):464-472. [PubMed: 22983573]

25. Lee CD, Blair SN. Cardiorespiratory fitness and smoking-related and total cancer mortality in men. Med Sci Sports Exerc 2002;34(5):735-739. [PubMed: 11984287]

26. Lee CD, Blair SN. Cardiorespiratory fitness and stroke mortality in men. Med Sci Sports Exerc 2002;34(4):592-595. [PubMed: 11932565]

27. Ekelund LG, Haskell WL, Johnson JL, Whaley FS, Criqui MH, Sheps DS. Physical fitness as a predictor of cardiovascular mortality in asymptomatic North American men. The Lipid Research Clinics Mortality Follow-up Study. N Engl J Med 1988;319(21):1379-1384. [PubMed: 3185648]

28. Blair SN, Kohl HW 3rd, Paffenbarger RS Jr., Clark DG, Cooper KH, Gibbons LW. Physical fitness and all-cause mortality. A prospective study of healthy men and women. JAMA 1989;262(17): 2395-2401. [PubMed: 2795824]

29. Wei M, Kampert JB, Barlow CE, et al. Relationship between low cardiorespiratory fitness and mortality in normal-weight, overweight, and obese men. JAMA 1999;282(16):1547-1553. [PubMed: 10546694]

30. Gulati M, Pandey DK, Arnsdorf MF, et al. Exercise capacity and the risk of death in women: the St James Women Take Heart Project. Circulation 2003;108(13):1554-1559. [PubMed: 12975254]

31. Mora S, Redberg RF, Cui Y, et al. Ability of exercise testing to predict cardiovascular and all-cause death in asymptomatic women: a 20-year follow-up of the lipid research clinics prevalence study. JAMA 2003;290(12):1600-1607. [PubMed: 14506119]

32. Blair SN, Goodyear NN, Gibbons LW, Cooper KH. Physical fitness and incidence of hypertension in healthy normotensive men and women. JAMA 1984;252(4):487-490. [PubMed: 6737638] 
33. Kraus WE, Houmard JA, Duscha BD, et al. Effects of the amount and intensity of exercise on plasma lipoproteins. N Engl J Med 2002;347(19):1483-1492. [PubMed: 12421890]

34. Sternfeld B, Sidney S, Jacobs DR Jr., Sadler MC, Haskell WL, Schreiner PJ. Seven-year changes in physical fitness, physical activity, and lipid profile in the CARDIA study. Coronary Artery Risk Development in Young Adults. Ann Epidemiol 1999;9(1):25-33. [PubMed: 9915606]

35. Wei M, Gibbons LW, Mitchell TL, Kampert JB, Lee CD, Blair SN. The association between cardiorespiratory fitness and impaired fasting glucose and type 2 diabetes mellitus in men. Ann Intern Med 1999;130(2):89-96. [PubMed: 10068380]

36. Laaksonen DE, Lakka HM, Salonen JT, Niskanen LK, Rauramaa R, Lakka TA. Low levels of leisure-time physical activity and cardiorespiratory fitness predict development of the metabolic syndrome. Diabetes Care 2002;25(9):1612-1618. [PubMed: 12196436]

37. Gaston M, Smith J, Gallagher D, et al. Recruitment in the Cooperative Study of Sickle Cell Disease (CSSCD). Control Clin Trials 1987;8(4 Suppl):131S-140S. [PubMed: 3440386]

38. Platt OS, Thorington BD, Brambilla DJ, et al. Pain in sickle cell disease. Rates and risk factors. N Engl J Med 1991;325(1):11-16. [PubMed: 1710777]

39. Castro O, Brambilla DJ, Thorington B, et al. The acute chest syndrome in sickle cell disease: incidence and risk factors. The Cooperative Study of Sickle Cell Disease. Blood 1994;84(2):643649. [PubMed: 7517723]

40. Artero EG, Jackson AS, Sui X, et al. Longitudinal algorithms to estimate cardiorespiratory fitness: associations with nonfatal cardiovascular disease and disease-specific mortality. J Am Coll Cardiol 2014;63(21):2289-2296. [PubMed: 24703924]

41. Carnethon MR, Gidding SS, Nehgme R, Sidney S, Jacobs DR, Jr., Liu K. Cardiorespiratory fitness in young adulthood and the development of cardiovascular disease risk factors. JAMA 2003;290(23):3092-3100. [PubMed: 14679272]

42. Jimenez-Pavon D, Artero EG, Lee DC, et al. Cardiorespiratory Fitness and Risk of Sudden Cardiac Death in Men and Women in the United States: A Prospective Evaluation From the Aerobics Center Longitudinal Study. Mayo Clin Proc 2016;91(7):849-857. [PubMed: 27378037]

43. Shah RV, Murthy VL, Colangelo LA, et al. Association of Fitness in Young Adulthood With Survival and Cardiovascular Risk: The Coronary Artery Risk Development in Young Adults (CARDIA) Study. JAMA Intern Med 2016;176(1):87-95. [PubMed: 26618471]

44. Pollock ML, Foster C, Schmidt D, Hellman C, Linnerud AC, Ward A. Comparative analysis of physiologic responses to three different maximal graded exercise test protocols in healthy women. Am Heart J 1982;103(3):363-373. [PubMed: 7064770]

45. Pollock ML, Miller HS Jr., Linnerud AC, Coleman E, Laughridge EE, Ward A. Follow up study on the effects of conditioning four days per week on the physical fitness of adult men. Am Correct Ther J 1974;28(5):135-139. [PubMed: 4423277]

46. Quanjer PH, Stanojevic S, Cole TJ, et al. Multi-ethnic reference values for spirometry for the 3-95yr age range: the global lung function 2012 equations. Eur Respir J 2012;40(6):1324-1343. [PubMed: 22743675]

47. Stocks J, Quanjer PH. Reference values for residual volume, functional residual capacity and total lung capacity. ATS Workshop on Lung Volume Measurements. Official Statement of The European Respiratory Society. Eur Respir J 1995;8(3):492-506. [PubMed: 7789503]

48. American Thoracic Society. Lung function testing: selection of reference values and interpretative strategies. Am Rev Respir Dis 1991;144(5):1202-1218. [PubMed: 1952453]

49. Pellegrino R, Viegi G, Brusasco V, et al. Interpretative strategies for lung function tests. Eur Respir J 2005;26(5):948-968. [PubMed: 16264058]

50. Anthi A, Machado RF, Jison ML, et al. Hemodynamic and functional assessment of patients with sickle cell disease and pulmonary hypertension. Am J Respir Crit Care Med 2007;175(12):12721279. [PubMed: 17379852]

51. Charlot K, Waltz X, Hedreville M, et al. Impaired oxygen uptake efficiency slope and off-transient kinetics of pulmonary oxygen uptake in sickle cell anemia are associated with hemorheological abnormalities. Clin Hemorheol Microcirc 2014. 
52. de Lima-Filho NN, Figueiredo MS, Vicari P, et al. Exercise-Induced Abnormal Increase of Systolic Pulmonary Artery Pressure in Adult Patients With Sickle Cell Anemia: An Exercise Stress Echocardiography Study. Echocardiography 2016;33(12):1880-1890. [PubMed: 25521187]

53. Miller GJ, Serjeant GR, Sivapragasam S, Petch MC. Cardio-pulmonary responses and gas exchange during exercise in adults with homozygous sickle-cell disease (sickle-cell anaemia). Clin Sci 1973;44(2):113-128. [PubMed: 4723270]

54. Oyono-Enguelle S, Le Gallais D, Lonsdorfer A, et al. Cardiorespiratory and metabolic responses to exercise in HbSC sickle cell patients. Med Sci Sports Exerc 2000;32(4):725-731. [PubMed: 10776889]

55. Berry JD, Willis B, Gupta S, et al. Lifetime risks for cardiovascular disease mortality by cardiorespiratory fitness levels measured at ages 45,55 , and 65 years in men. The Cooper Center Longitudinal Study. J Am Coll Cardiol 2011;57(15):1604-1610. [PubMed: 21474041]

56. Defina LF, Willis BL, Radford NB, et al. The association between midlife cardiorespiratory fitness levels and later-life dementia: a cohort study. Annals of internal medicine 2013;158(3):162-168. [PubMed: 23381040]

57. Gupta S, Rohatgi A, Ayers CR, et al. Cardiorespiratory fitness and classification of risk of cardiovascular disease mortality. Circulation 2011;123(13):1377-1383. [PubMed: 21422392]

58. Duncan GE, Li SM, Zhou XH. Cardiovascular fitness among U.S. adults: NHANES 1999-2000 and 2001-2002. Med Sci Sports Exerc 2005;37(8):1324-1328. [PubMed: 16118579]

59. Sanders LF, Duncan GE. Population-based reference standards for cardiovascular fitness among U.S. adults: NHANES 1999-2000 and 2001-2002. Med Sci Sports Exerc 2006;38(4):701-707. [PubMed: 16679986]

60. Howden EJ, Weston K, Leano R, et al. Cardiorespiratory fitness and cardiovascular burden in chronic kidney disease. J Sci Med Sport 2015;18(4):492-497. [PubMed: 25127529]

61. Pate RR, Wang CY, Dowda M, Farrell SW, O’Neill JR. Cardiorespiratory fitness levels among US youth 12 to 19 years of age: findings from the 1999-2002 National Health and Nutrition Examination Survey. Arch Pediatr Adolesc Med 2006;160(10):1005-1012. [PubMed: 17018458]

62. Hunter GR, Weinsier RL, McCarthy JP, Enette Larson-Meyer D, Newcomer BR. Hemoglobin, muscle oxidative capacity, and VO2max in African-American and Caucasian women. Med Sci Sports Exerc 2001;33(10):1739-1743. [PubMed: 11581560]

63. Carter R, Nicotra B, Blevins W, Holiday D. Altered exercise gas exchange and cardiac function in patients with mild chronic obstructive pulmonary disease. Chest 1993;103(3):745-750. [PubMed: 8449062]

64. Elbehairy AF, Ciavaglia CE, Webb KA, et al. Pulmonary Gas Exchange Abnormalities in Mild Chronic Obstructive Pulmonary Disease. Implications for Dyspnea and Exercise Intolerance. Am J Respir Crit Care Med 2015;191(12):1384-1394. [PubMed: 25826478]

65. Ginde S, Bartz PJ, Hill GD, et al. Restrictive lung disease is an independent predictor of exercise intolerance in the adult with congenital heart disease. Congenital heart disease 2013;8(3):246-254. [PubMed: 23075089]

66. Marciniuk DD, Watts RE, Gallagher CG. Dead space loading and exercise limitation in patients with interstitial lung disease. Chest 1994;105(1):183-189. [PubMed: 8275730]

67. Martis N, Queyrel-Moranne V, Launay D, et al. Limited Exercise Capacity in Patients with Systemic Sclerosis: Identifying Contributing Factors with Cardiopulmonary Exercise Testing. J Rheumatol 2017.

68. Benck LR, Cuttica MJ, Colangelo LA, et al. Association between Cardiorespiratory Fitness and Lung Health from Young Adulthood to Middle Age. Am J Respir Crit Care Med 2017;195(9): 1236-1243. [PubMed: 28248551]

69. Blair SN, Kampert JB, Kohl HW 3rd, et al. Influences of cardiorespiratory fitness and other precursors on cardiovascular disease and all-cause mortality in men and women. Jama 1996;276(3):205-210. [PubMed: 8667564]

70. Kokkinos P, Myers J, Kokkinos JP, et al. Exercise capacity and mortality in black and white men. Circulation 2008;117(5):614-622. [PubMed: 18212278]

71. Reusch JE, Bridenstine M, Regensteiner JG. Type 2 diabetes mellitus and exercise impairment. Rev Endocr Metab Disord 2013. 
72. Dedeken L, Chapusette R, Le PQ, et al. Reduction of the six-minute walk distance in children with sickle cell disease is correlated with silent infarct: results from a cross-sectional evaluation in a single center in Belgium. PloS one 2014;9(9):e108922. [PubMed: 25275451]

73. Sil S, Cohen LL, Dampier C. Psychosocial and Functional Outcomes in Youth With Chronic Sickle Cell Pain. The Clinical journal of pain 2016;32(6):527-533. [PubMed: 26379074] 


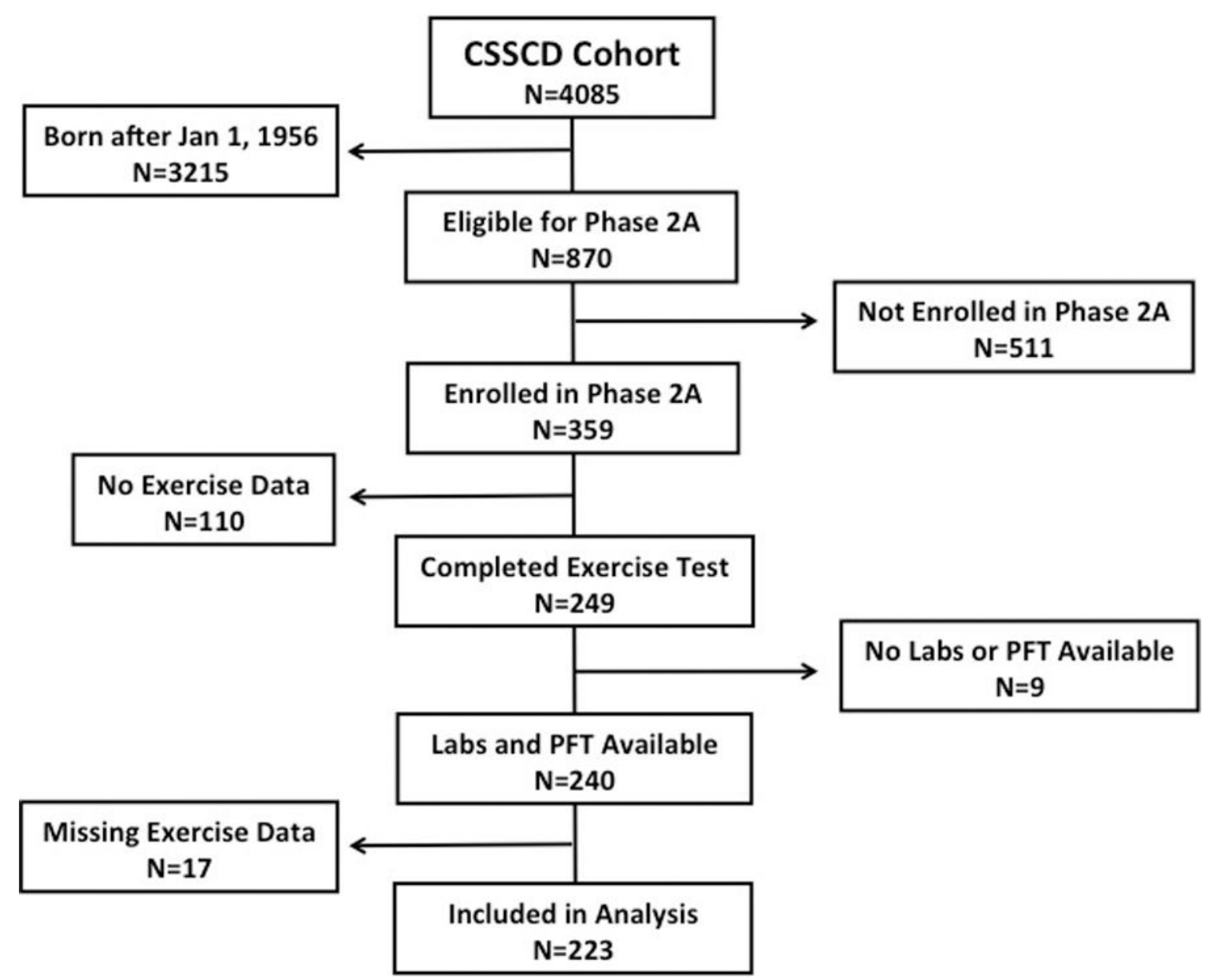

Figure 1.

Flow diagram of study participants enrolled in the CSSCD and their eligibility for inclusion in the analysis. 
Table 1.

Characteristics of participants in the CSSCD who completed or did not complete baseline exercise testing

\begin{tabular}{|c|c|c|c|c|c|}
\hline \multirow{2}{*}{ Variable } & \multicolumn{2}{|c|}{ Exercise test } & \multicolumn{2}{|c|}{ No exercise test } & \multirow{2}{*}{$p$ value } \\
\hline & $\mathbf{N}$ & Values & $\mathbf{N}$ & Values & \\
\hline Male, number $(\%)$ & 223 & $80(35.9)$ & 136 & $51(37.5)$ & 0.756 \\
\hline $\mathrm{SS}$ or $\mathrm{S} \beta^{0}$ thalassemia, number $(\%)$ & 221 & $154(69.7)$ & 136 & $101(74.3)$ & 0.352 \\
\hline Obstructive lung disease, number (\%) & 219 & $25(11.4)$ & 99 & $8(8.1)$ & 0.373 \\
\hline Restrictive lung disease, number (\%) & 220 & $38(17.3)$ & 99 & $22(22.2)$ & 0.295 \\
\hline Chronic transfusions, number $(\%)$ & 222 & $10(4.5)$ & 134 & $6(4.5)$ & 0.991 \\
\hline Hydroxyurea, number $(\%)$ & 227 & $5(2.2)$ & 136 & $3(2.2)$ & 0.990 \\
\hline Mortality, number died (\%) & 223 & $9(4.0)$ & 136 & 24 (17.6) & 0.001 \\
\hline $\mathrm{Age}^{\wedge},(\mathrm{yrs})$, mean $\pm \mathrm{SD}$ & 223 & $42.5 \pm 7.4$ & 136 & $44.0 \pm 8.3$ & 0.071 \\
\hline Follow-up (yrs), mean \pm SD & 223 & $3.1 \pm 0.5$ & 136 & $2.8 \pm 0.8$ & 0.001 \\
\hline $\mathrm{BMI}^{\wedge}$, mean $\pm \mathrm{SD}$ & 220 & $24.2 \pm 5.7$ & 132 & $23.7 \pm 5.3$ & 0.418 \\
\hline ACS hospitalization rate ${ }^{*}$, mean \pm SD & 223 & $0.04 \pm 0.13$ & 136 & $0.05 \pm 0.16$ & $0.630^{\prime}$ \\
\hline Pain hospitalization rate ${ }^{*}$, mean \pm SD & 223 & $0.31 \pm 1.11$ & 136 & $0.64 \pm 1.56$ & $0.0011^{\prime}$ \\
\hline WBCs, $\left(x 10^{3} / \mathrm{ml}\right)$, mean \pm SD & 223 & $10.8 \pm 3.8$ & 128 & $11.2 \pm 4.2$ & 0.476 \\
\hline Haemoglobin, $(\mathrm{g} / \mathrm{dL})$, mean \pm SD & 223 & $9.1 \pm 2.2$ & 128 & $8.8 \pm 2.2$ & 0.210 \\
\hline Platelet count, $\left(\times 10^{3} / \mathrm{ml}\right)$, mean $\pm \mathrm{SD}$ & 218 & $366.0 \pm 125.6$ & 123 & $345.9 \pm 139.1$ & 0.174 \\
\hline
\end{tabular}

ACS: acute chest syndrome; BMI: body mass index; SD: standard deviation; WBCs: white blood cells

Age and BMI at phase 2A study entry

Events per patient/year

'Mann-Whitney U test 
Table 2.

Summary of exercise data for participants in the CSSCD who completed one or two exercise tests

\begin{tabular}{|c|c|c|c|c|c|c|}
\hline \multirow{2}{*}{ Variable } & \multirow{2}{*}{$\mathbf{N}$} & \multirow{2}{*}{ All participants } & \multicolumn{4}{|c|}{ Participants with two exercise tests } \\
\hline & & & $\mathbf{N}$ & First test & Second test & $p$ value \\
\hline Duration on treadmill (minutes), mean \pm SD & 223 & $11.6 \pm 5.2$ & 100 & $12.1 \pm 5.0$ & $12.2 \pm 4.7$ & $0.764^{\#}$ \\
\hline Peak incline, mean \pm SD & 208 & $12.1 \pm 6.2$ & 79 & $12.3 \pm 5.5$ & $12.4 \pm 5.9$ & 0.882 \\
\hline METS, mean \pm SD & 223 & $5.9 \pm 1.7$ & 79 & $5.9 \pm 1.5$ & $5.9 \pm 1.6$ & 0.873 \\
\hline \multicolumn{7}{|l|}{ Baseline, mean $\pm \mathrm{SD}$} \\
\hline HR (bpm) & 223 & $77.1 \pm 14.2$ & 97 & $75.6 \pm 14.0$ & $78.2 \pm 14.8$ & 0.05 \\
\hline Systolic BP (mm Hg) & 221 & $119.0 \pm 17.1$ & 97 & $114.9 \pm 14.3$ & $120.4 \pm 16.3$ & 0.002 \\
\hline \multicolumn{7}{|l|}{ End of study, mean \pm SD } \\
\hline HR (bpm) & 220 & $151.8 \pm 21.2$ & 90 & $153.2 \pm 23.8$ & $149.5 \pm 18.9$ & 0.111 \\
\hline Systolic BP (mm Hg) & 211 & $163.4 \pm 30.2$ & 80 & $157.2 \pm 25.8$ & $162.3 \pm 23.9$ & 0.123 \\
\hline RPE & 213 & $8.3 \pm 2.2$ & 95 & $8.5 \pm 2.0$ & $8.1 \pm 2.9$ & $0.403^{\#}$ \\
\hline \multicolumn{7}{|l|}{ Stage completed, number $(\%)$} \\
\hline 0 & 223 & $5(2.2)$ & 99 & $1(1.0)$ & $1(1.0)$ & \multirow{6}{*}{$0.784^{\#}$} \\
\hline $1-2$ & 223 & $25(11.2)$ & 99 & $8(8.1)$ & $9(9.1)$ & \\
\hline $3-4$ & 223 & $51(22.9)$ & 99 & $25(25.3)$ & $22(22.2)$ & \\
\hline $5-6$ & 223 & $56(25.1)$ & 99 & $28(28.3)$ & $33(33.3)$ & \\
\hline $7-8$ & 223 & $48(21.5)$ & 99 & $19(19.2)$ & $16(16.2)$ & \\
\hline $9-10$ & 223 & $38(17.0)$ & 99 & $18(18.2)$ & $18(18.2)$ & \\
\hline \multicolumn{7}{|l|}{ Symptoms, number (\%) } \\
\hline Chest pain & 223 & $6(2.7)$ & 99 & $5(5.1)$ & $5(5.1)$ & $1.00^{\#}$ \\
\hline Dyspnea & 223 & $69(30.9)$ & 99 & $28(28.3)$ & $41(41.4)$ & $0.016{ }^{\#}$ \\
\hline Dizziness & 223 & $13(5.8)$ & 99 & $8(8.1)$ & $6(6.1)$ & $0.564^{\#}$ \\
\hline
\end{tabular}

BP: blood pressure; HR: heart rate; METS; Metabolic Equivalent of Task; RPE: Rated Perceived Exertion; SD: standard deviation

\#Wilcoxon signed ranks test 
Table 3.

Factors associated with exercise capacity among participants in the CSSCD

\begin{tabular}{|c|c|c|c|c|c|}
\hline Variable & $\mathbf{N}$ & $\begin{array}{c}\text { Low Fitness } \\
\text { Tertile }(\mathbf{N}=74)\end{array}$ & $\begin{array}{c}\text { Intermediate } \\
\text { Fitness Tertile } \\
\quad(\mathbf{N}=\mathbf{8 4})\end{array}$ & $\begin{array}{l}\text { High Fitness } \\
\text { Tertile }(\mathbf{N}=65)\end{array}$ & $p$ value* \\
\hline Age (years), mean \pm SD & 223 & $45.2 \pm 8.2$ & $43.1 \pm 7.5$ & $41.3 \pm 6.0$ & 0.007 \\
\hline $\mathrm{SS}$ or $\mathrm{S} / \beta^{0}$ thalassemia, number $(\%)$ & 222 & $58(79.5)$ & $55(66.3)$ & $41(63.1)$ & 0.078 \\
\hline Male sex, number $(\%)$ & 223 & $17(23)$ & $24(28.6)$ & $39(60)$ & $<0.001$ \\
\hline Baseline haemoglobin $(\mathrm{g} / \mathrm{dL})$, mean $\pm \mathrm{SD}$ & 223 & $8.5 \pm 2.1$ & $9.0 \pm 2.1$ & $9.8 \pm 2.2$ & 0.003 \\
\hline Baseline WBC $\left(\times 10^{3} / \mathrm{ml}\right)$, mean $\pm \mathrm{SD}$ & 223 & $11.5 \pm 4.3$ & $10.6 \pm 3.4$ & $10.3 \pm 3.5$ & 0.139 \\
\hline BMI at fitness test, mean \pm SD & 194 & $25.1 \pm 7.1$ & $25.2 \pm 5.8$ & $23.3 \pm 4.6$ & 0.111 \\
\hline Duration on treadmill (min), mean \pm SD & 223 & $5.7 \pm 1.9$ & $11.8 \pm 1.6$ & $18.1 \pm 2.1$ & $<0.001$ \\
\hline Peak incline, mean $\pm \mathrm{SD}$ & 208 & $5.4 \pm 2.6$ & $12.5 \pm 2.2$ & $19.8 \pm 2.8$ & $<0.001$ \\
\hline METS, mean \pm SD & 208 & $4.0 \pm 0.7$ & $6.0 \pm 0.6$ & $8.0 \pm 0.8$ & $<0.001$ \\
\hline Abnormal PFT, number (\%) & 220 & $42(58.3)$ & $29(34.9)$ & $25(38.5)$ & 0.008 \\
\hline $\begin{array}{l}\text { Pain hospitalization rate, } 3 \text { year retrospective, mean } \\
\pm \mathrm{SD}\end{array}$ & 223 & $0.38 \pm 0.00$ & $0.33 \pm 0.00$ & $0.31 \pm 0.00$ & $0.630^{\#}$ \\
\hline $\begin{array}{l}\text { ACS hospitalization rate, } 3 \text { year retrospective, mean } \\
\pm \mathrm{SD}\end{array}$ & 223 & $0.03 \pm 0.00$ & $0.06 \pm 0.00$ & $0.03 \pm 0.00$ & $0.426^{\#}$ \\
\hline
\end{tabular}

ACS: acute chest syndrome; BMI: body mass index; METS: Metabolic Equivalent of Task; PFT: pulmonary function test; SD: standard deviation; WBCs: white blood cells

$\hat{\imath}$

Exercise capacity defined by the duration on treadmill in minutes

*

ANOVA for comparing means and chi-square test for comparing percentages, unless otherwise noted

${ }^{\#}$ Kruskal-Wallis test 
Table 4.

Multivariable tobit regression model for factors associated with fitness $(\mathrm{N}=215)$

\begin{tabular}{|l|c|c|c|}
\hline & $\boldsymbol{\beta}$ Coefficient $\mathbf{( 9 5 \%}$ CI) & SE & $\boldsymbol{p}$ value \\
\hline Gender (female) & $-3.34(-1.80,-4.88)$ & 0.78 & $<\mathbf{0 . 0 0 1}$ \\
\hline Genotype (SS or S/ $\beta^{0}$ thalassemia) & $-1.78(-4.23,0.66)$ & 1.24 & 0.152 \\
\hline Age (years) & $-0.14(-0.24,-0.04)$ & 0.05 & $\mathbf{0 . 0 0 5}$ \\
\hline Haemoglobin (g/dL) & $0.56(0.08,1.04)$ & 0.24 & $\mathbf{0 . 0 2 3}$ \\
\hline Abnormal PFT & $-1.42(-2.92,0.07)$ & 0.76 & 0.061 \\
\hline BMI at study entry & $-0.23(-0.37,-0.09)$ & 0.07 & $\mathbf{0 . 0 0 1}$ \\
\hline Pain hospitalization rate & $0.22(-0.48,0.92)$ & 0.36 & 0.538 \\
\hline ACS hospitalization rate & $-0.99(-6.73,4.76)$ & 2.91 & 0.735 \\
\hline
\end{tabular}

ACS: acute chest syndrome; BMI: body mass index; CI: confidence interval; PFT: pulmonary function test; SE: standard error

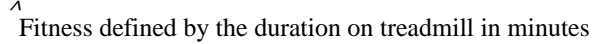


Table 5.

Multivariable negative binomial regression model for predicting pain and ACS hospitalizations $(\mathrm{N}=187)$

\begin{tabular}{|c|c|c|c|c|c|c|}
\hline & \multicolumn{3}{|c|}{ Prospective ACS Rate } & \multicolumn{3}{|c|}{ Prospective Pain Rate } \\
\hline & IRR & $95 \% \mathrm{CI}$ & $p$ value & IRR & $95 \% \mathrm{CI}$ & $p$ value \\
\hline Gender (male) & 1.80 & $0.66,4.90$ & 0.25 & 0.78 & $0.33,1.85$ & 0.58 \\
\hline Genotype (SS or $S / \beta^{0}$ thalassemia) & 1.86 & $0.36,9.62$ & 0.46 & 2.74 & $0.76,9.95$ & 0.13 \\
\hline Age at exercise test (years) & 0.99 & $0.90,1.08$ & 0.78 & 0.96 & $0.88,1.03$ & 0.24 \\
\hline Haemoglobin $(\mathrm{g} / \mathrm{dL})$ & 1.21 & $0.90,1.64$ & 0.21 & 1.02 & $0.78,1.33$ & 0.9 \\
\hline Retrospective 3 year ACS hospitalization rate & 31.60 & $4.68,213.48$ & $<0.001$ & N/A & N/A & N/A \\
\hline Retrospective 3 year pain hospitalization rate & N/A & N/A & N/A & 3.29 & $2.56,4.23$ & $<0.001$ \\
\hline Exercise capacity $^{\wedge}$ & 0.95 & $0.85,1.07$ & 0.41 & 1.00 & $0.91,1.10$ & 0.92 \\
\hline Abnormal pulmonary function test & 1.54 & $0.56,4.23$ & 0.41 & 1.28 & $0.56,2.92$ & 0.55 \\
\hline
\end{tabular}

ACS: acute chest syndrome; CI: confidence interval; IRR: Incidence Rate Ratio; N/A: not applicable

\# Prospective hospitalization rates for pain and ACS were calculated using events after exercise testing with $\geq 6$ month follow up

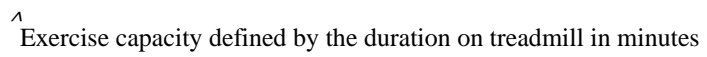


Table 6.

Cox regression model for survival and predictors of mortality $(\mathrm{N}=176)$

\begin{tabular}{|l|c|c|}
\hline & Hazard Ratio $(95 \%$ CI) & $\boldsymbol{p}$ value \\
\hline Gender (male) & $6.47(1.24,33.88)$ & $\mathbf{0 . 0 2}$ \\
\hline Age (years) & $1.06(0.97,1.16)$ & 0.22 \\
\hline Haemoglobin $(\mathrm{g} / \mathrm{dL})$ & $0.55(0.37,0.84)$ & $\mathbf{0 . 0 0 5}$ \\
\hline Exercise capacity ${ }^{\wedge}$ & $0.98(0.85,1.13)$ & 0.82 \\
\hline Abnormal pulmonary function test & $1.04(0.22,4.86)$ & 0.96 \\
\hline
\end{tabular}

CI: confidence interval

$\wedge$

Exercise capacity defined by the duration on treadmill in minutes

Note: Sickle cell genotype ( $\mathrm{SS}$ or $\mathrm{S} / \beta^{0}$ thalassemia) is not included in the model because patients with non-SS or $\mathrm{S} / \beta^{0}$ thalassemia had no deaths, and so the model does not converge to a stable solution. 